\title{
Effect of Unilateral Pulmonary Artery Occlusion on Pulmonary Circulation in Patients with Pulmonary Hypertension in Mitral Stenosis
}

\author{
J. WIDIMSKÝ, J. HURYCH, V. STANĚK, AND J. KASALICKÝ \\ From the Institute for Cardiovascular Research, Praha KrČ, Czechoslovakia
}

In patients suffering from mitral stenosis, the pulmonary vascular resistance is extremely high in 12 per cent and considerably increased in another 16 per cent of patients (Wood, 1956, 1958). Eighty per cent of such patients have no history of haemoptysis, pulmonary oedema, paroxysmal nocturnal dyspnoea, or orthopnoea; and some of them do not even have exertional dyspnoea.

The first symptoms that make the patient visit a physician are those induced by severe pulmonary hypertension and low cardiac output (such as fatigue, pain in the hepatic region, and oedema). In some of these patients both pulmonary hypertension and pulmonary vascular resistance may be reduced by the administration of acetylcholine (Harris, 1957; Wocd et al., 1957; Söderholm and Werkö, 1959; Söderholm, Werkö, and Widimský, $1962)$; in these patients active vasoconstriction is a factor in the maintenance of the raised pulmonary vascular resistance. Charms, Brofman, and Kohn, (1959) found that pulmonary artery occlusion in patients with mitral stenosis and severe pulmonary hypertension was accompanied by surprisingly small increases in the pulmonary arterial pressure, suggesting that the vascular resistance in the nonoccluded lung dropped abruptly. In the present study we investigated the reaction of the pulmonary vascular bed in mitral stenosis to increased flow rate, and compared cases of unilateral pulmonary artery occlusion in which the flow rate was increased only in one lung, with the effects of muscular exercise, in which the bilateral pulmonary flow rate was increased.

\section{SUBJECTS AND METHODS}

The effect of unilateral pulmonary occlusion by means of a balloon catheter on central haemodynamics was

Received March 14, 1968. studied in 14 patients with pulmonary hypertension due to mitral stenosis. In all patients central haemodynamics and respiration were examined at rest and during right or left pulmonary artery occlusion; in 10 patients the occlusion period was followed by a rest period (20-25 min.), followed in turn by an exercise period in the supine position on a bicycle ergometer at a load of $100-250 \mathrm{kp} . \mathrm{m} . / \mathrm{min}$. The feasibility of this procedure had been established with repeated occlusions by Widimský, Kasalický, and Berglund (1964). The pulmonary artery occlusion was complete as could be judged by the following criteria.

(1) The pressure trace distal to the balloon was the same as the wedge pressure curve.

(2) No dilution curve could be recorded from the aorta after indocyanine green was injected distal to the balloon.

All patients were examined in the morning after a light breakfast. Under local anaesthesia a three-way Dotter-Lucas catheter was inserted through the cubital vein into the pulmonary artery, and a Kifa catheter was introduced percutaneously from the femoral artery to below the aortic arch by the Seldinger technique. In 3 patients a catheter was inserted transseptally into the left atrium by the Ross method. In 3 other patients another catheter was inserted into the right atrium retrogradely from the femoral vein by the Seldinger technique.

Pressures were measured using Elema electromanometers and recorded by a direct-writing Cardirex (Siemens) apparatus. The zero level was taken as $5 \mathrm{~cm}$. below the angle of Louis. Cardiac output was measured in 5 patients by the Fick principle. The subjects breathed through a mouthpiece into a Douglas bag for 3-5 minutes, and the $\mathrm{CO}_{2}$ and $\mathrm{O}_{2}$ content of the expired air was estimated with the aid of a Zeiss interferometer. In the 2nd minute of breathing into the bag, blood samples were simultaneously withdrawn from the pulmonary and brachial arteries. Blood oxygen saturations were estimated using a Brinkman haemoreflectometer (Kipp), and haemoglobin concentrations were determined photometrically. In 9 patients the cardiac output was measured by the dye dilution technique as follows: 
indocyanine green was injected into the pulmonary artery in amounts of $0.7-1.2 \mathrm{ml}$. of a $5 \mathrm{mg} . / \mathrm{ml}$. solution. Blood was sucked through a densitometer at a constant rate by means of a pump, from a catheter with the tip situated just below the aortic arch. The suction rates were either 0.6 or $1.2 \mathrm{ml}$./ $/ \mathrm{sec}$. The densitometer and the recording device were the Cambridge Dye Dilution Outfit Mark II.

Pressure measurements, and the collection of expired gas and blood samples were made between the 7th and the 12th minute of occlusion.

Total pulmonary resistance at rest and during exercise was calculated from the formula:

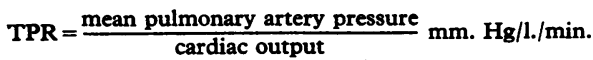

and that during occlusion from the formula:

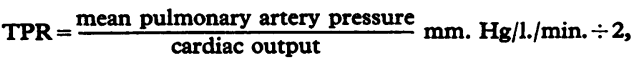

it being assumed that the blood flow through both lungs is equal.

Pulmonary vascular resistance at rest and during exercise was calculated from the formula:

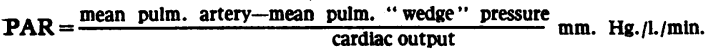
and during occlusion the value thus obtained was again divided by 2 .

Total peripheral resistance was calculated from the formula:

$$
\mathrm{SR}=\frac{\text { mean aortic pressure }}{\text { cardiac output }} \mathrm{mm} . \mathrm{Hg} / \mathrm{l} . / \mathrm{min} \text {. }
$$

\section{RESULTS}

Table I shows the haemodynamic findings in individual patients, while Table II gives mean values for all the patients. From Table $I$ it is evident that in patients with severe pulmonary hypertension only a small increase in the mean pulmonary arterial pressure occurs when one pulmonary artery branch is occluded, and in some patients the pulmonary arterial pressure remains practically unchanged. Since the cardiac output remained substantially unchanged, this indicates an abrupt drop in vascular resistance in the unoccluded lung. From Table $I$ it is evident that during occlusion both the total pulmonary resistance and the pulmonary vascular resistance are significantly decreased, arterial oxygen saturation is slightly increased, and the remaining parameters are unchanged.

Central haemodynamics during exercise were investigated in 10 patients. While the total pulmonary resistance and the pulmonary vascular resistance decreased significantly during occlusion, they either did not change or they even increased during exercise (Fig. 1 and 2). When the left pulmonary artery branch was occluded, the mean pulmonary arterial pressure increased slightly, the cardiac output decreased to some extent, and the pulmonary vascular resistance decreased substantially (Fig. 1). During exercise the mean pulmonary arterial pressure increased conspicuously. This increase cannot be explained by increased pulmonary blood flow, since the increase was small; nor by tachycardia and increased left atrial pressure. The latter increased substantially less than that of the pulmonary arterial pressure, the pressure gradient in the pulmonary circulation thereby being considerably increased, and the pulmonary vascular resistance increased greatly as well. Likewise when the right pulmonary artery was occluded (Fig. 2) a conspicuous discrepancy was apparent between the behaviour of the pulmonary vascular resistance during occlusion and during exercise.

\section{DISCUSSION}

Patients with cardiac disorders of various aetiologies may show changes in the pulmonary circulation during exercise similar to those observed in patients with mitral stenosis (Werkö, 1964). A constant finding, however, is that of aggravated pulmonary hypertension during muscular work in patients with mitral stenosis. In such patients the left atrial pressure is abnormally high during exercise, first because of the increased flow rate and secondly because of a shorter diastolic period due to tachycardia (Gorlin et al., 1951a).

The cardiac output during exercise in patients with mitral stenosis increases less than in healthy subjects (Hickam and Cargill, 1948; Gorlin et al., 1951b); the higher the pulmonary hypertension, the less favourable is the reaction of the cardiac output to exercise (Harris and Heath, 1962).

If the pulmonary arterial resistance is normal at rest in patients with mitral stenosis, it usually does not alter or it decreases slightly during exercise. Some patients, however, show a conspicuous increase in resistance during exercise; this applies, as a rule, to patients whose pulmonary resistance is already high at rest. At the same time, the cardiac output usually remains unchanged (Bayliss, Etheridge, and Hyman, 1950; Eliasch, Wade, and Werkö, 1952; Donald, 1959; Semler, Shepherd, and Wood, 1959; Harris and Heath, 1962). Such increase in pulmonary vascular resistance during exercise is shown in Fig. 1 and 2.

High pulmonary vascular resistance imposes a substantial load on the right heart and may produce right heart failure. A consequence of this is a lower cardiac output during exercise and hence also a lesser increase in the left atrial pressure during exercise.

At the same time, however, high pulmonary vascular resistance protects the pulmonary capillary 
TABLE I

EFFECT OF PULMONARY ARTERY OCCLUSION AND EXERCISE ON CENTRAL HAEMODYNAMICS IN PATIENTS WITH MITRAL STENOSIS

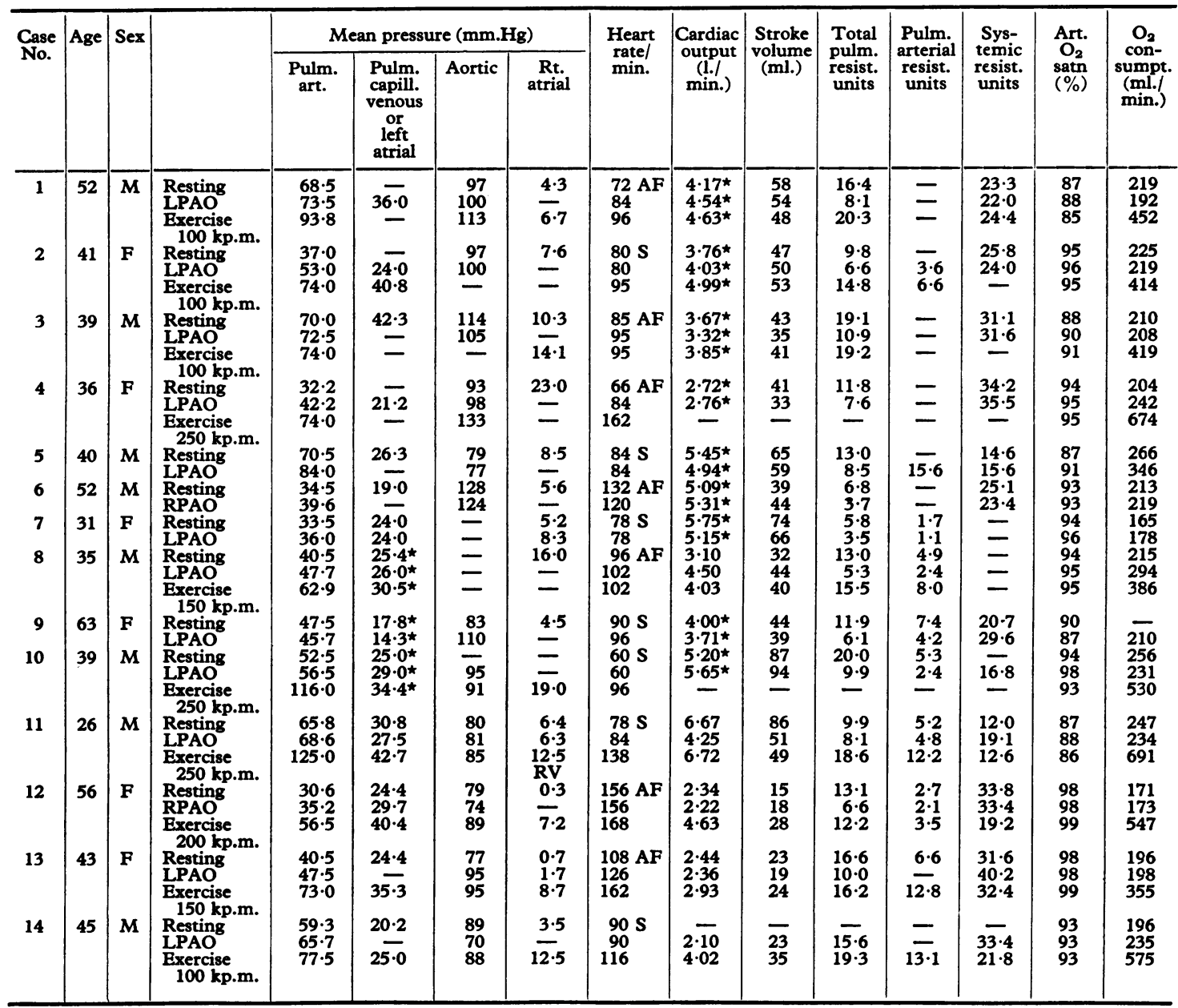

RPAO, right pulmonary artery occlusion; LPAO, left pulmonary artery occlusion; AF, atrial fibrillation; S, sinus rhythm.

* Cardiac output measured by dye dilution technique.

bed from increased cardiac output of the right heart. According to Wade (1960), however, this may be an accidental finding rather than a proof of a teleologically beneficial reflex, since this occurs only in a few patients with tight mitral stenosis.

Davies, Goodwin, and Van Leuven (1954) reported a higher incidence of paroxysmal dyspnoea in patients with active pulmonary hypertension than in those without. Severe pulmonary hypertension is a serious complication of mitral stenosis, indicating an unfavourable prognosis, and is often accompanied by gradual aggravation of the clinical state. Nevertheless, it is difficult to decide whether heart failure, frequent in patients with severe pulmonary hypertension, has been preceded by increased pulmonary vascular resistance, or whether the contrary is true (Werkö, 1964).

Pulmonary arterial pressure during exercise attained extreme values in some of our patients. The left atrial or the "capillary-venous" pressures also increased simultaneously, but the increase in the pulmonary arterial pressure was so high that the pressure gradient increased substantially during exercise.

The increase in pulmonary vascular resistance can hardly be explained except by active vasoconstriction. This concept is also supported by the finding of Söderholm et al. (1962) that the 
raised pulmonary arterial pressure and resistance, which occurs during exercise in patients with mitral stenosis, may be counteracted by acetylcholine infused into the right atrium.

During pulmonary artery occlusion, however, the pulmonary arterial pressure increased surprisingly little in some patients with mitral stenosis. If we assume that the resistance during the rest period is uniformly divided between both lungs (Denolin, 1961), our results show clearly that during occlusion the resistance of the non-occluded lung must sink practically to a half of the initial value, since the blood flow doubled in comparison with the initial level and the pressure gradient remained substantially unchanged.

Reactions to occlusion of the pulmonary artery may be divided into two groups according to the behaviour of the pulmonary vascular resistance in
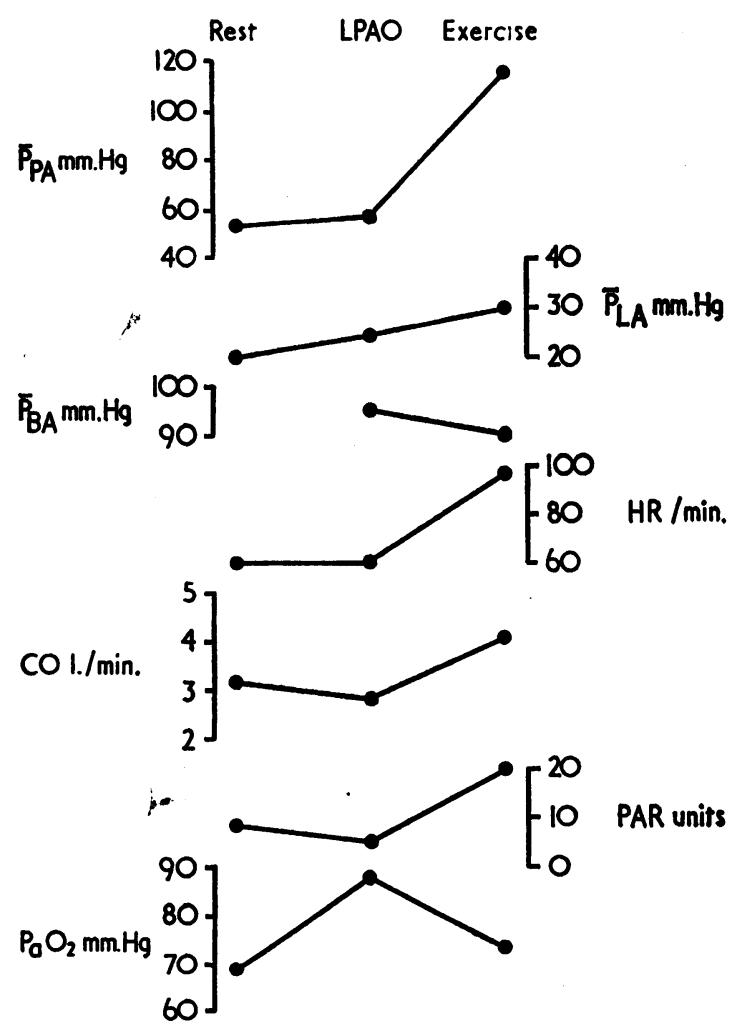

Fig. 1.-Central haemodynamics at rest, during left pulmonary artery occlusion (LPAO), and during exercise in a 38-year-old patient with mitral stenosis (Case 10). $\overline{\mathrm{P}}_{\mathrm{PA}}$, mean pulmonary arterial pressure; $\overline{\mathbf{P}}_{\mathrm{LA}}$, mean left atrial pressure; $\overline{\mathbf{P}}_{\mathrm{BA}}$, mean brachial arterial pressure; $\mathrm{HR}$, heart rate; $\mathrm{CO}$, cardiac output; PAR, pulmonary arteriolar resistance; $\mathrm{P}_{\mathrm{R}} \mathrm{O}_{2}$,
TABLE II

EFFECT OF UNILATERAL PULMONARY ARTERY OCCLUSION ON CENTRAL HAEMODYNAMICS IN MITRAL STENOSIS (Means of values in Table I)

\begin{tabular}{l|c|c|c}
\hline & Rest & $\begin{array}{c}\text { Pulm. } \\
\text { art. } \\
\text { occlu- } \\
\text { sion }\end{array}$ & $\begin{array}{c}\text { Proba- } \\
\text { bility }\end{array}$ \\
\hline Mean pulm. art. pressure (mm. Hg) & 48.8 & 54.8 & $<0.001$ \\
Mean pulm. "capillary venous" pres- & 25.4 & 25.7 & $>0.05$ \\
sure (mm. Hg) & 92.4 & 94.1 & $>0.05$ \\
Mean aortic pressure (mm. Hg) & 91 & 96 & $>0.05$ \\
Heart rate/min. & $4 \cdot 18$ & 3.92 & $>0.05$ \\
Cardiac output (1./min.) & 50 & 45 & $>0.05$ \\
Stroke volume (ml.) & 12.86 & 7.91 & $<0.001$ \\
Total pulm. resist. (units) & 4.82 & 2.96 & $<0.05$ \\
Pulm. arteriol. resist. (units) & 25.2 & 27.1 & $>0.05$ \\
Systemic resist. (units) & 92 & 93 & $<0.05$ \\
Art. O O $_{2}$ satn (\%) & 214 & 227 & $>0.05$ \\
O2 consumption (ml./min.) & & & \\
\hline
\end{tabular}

the non-occluded lung. The first group comprises patients with extensive lesions of lung parenchyma (e.g. in interstitial pulmonary fibrosis), in whom the major pulmonary vessels are likely to be affected first; in this group the pulmonary resistance is fixed, and pulmonary arterial occlusion is accompanied by a conspicuous increase in pulmonary hypertension (Widimský and Kasalický, 1964). The other group comprises patients with small

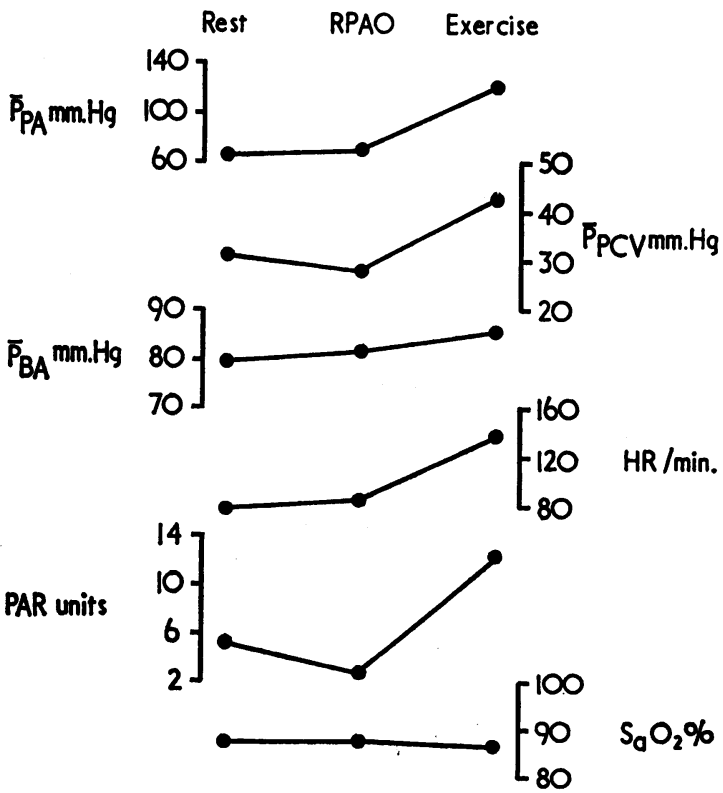

FIG. 2.-Central haemodynamics at rest, during right pulmonary artery occlusion, and during exercise in a 24-year-old patient with mitral stenosis and incompetence (Case 11). $\overline{\mathbf{P}}_{\mathrm{PCV}}$, mean pulmonary "capillary-venous" pressure; $\mathrm{SaO}_{2}$, arterial oxygen saturation. 
vessels affected, e.g. in consequence of mitral stenosis, and apparently also some types of congenital defect, such as the Eisenmenger complex (Brofman, 1959), or primary pulmonary hypertension (Charms, 1961). In this group pulmonary arterial occlusion is accompanied by only a slight increase in pulmonary hypertension in consequence of a much reduced pulmonary vascular resistance. It is interesting that severe pulmonary hypertension is accompanied by a greater reduction of the vascular resistance during pulmonary artery occlusion than is pulmonary hypertension of a minor degree.

Hyland et al. (1963) also found that, in embolized dogs, pulmonary arterial occlusion by means of a balloon, lowered the pulmonary vascular resistance more when the embolization-induced pulmonary hypertension was greater. This finding is not altogether surprising with regard to the shape of the curve representing the relation between pressure and pulmonary vascular bed volume (Fritts and Richards, 1960), and with regard to the vasodilatory effect of transmural pressure shown by Burton (1959). Nevertheless, the problem remains as to why the pulmonary vascular bed, which is capable of dilatation, does not dilate in severe pulmonary hypertension occurring, for example, in mitral stenosis.

The change in pulmonary blood flow during pulmonary artery occlusion and during exercise was not the same. It increased during exercise only slightly, and in 2 patients the change was less than 10 per cent of the initial value. During pulmonary artery occlusion, however, the pulmonary blood flow through the unoccluded lung doubled in most patients.

However, in spite of the fact that during exercise the pulmonary blood flow did not change, or increased only slightly, the pulmonary arterial pressure increased conspicuously, in contrast to pulmonary artery occlusion, where a significant increase in flow was accompanied by a minimal pressure increase in the lesser circulation.

These results show, therefore, that while an enhanced flow rate in the pulmonary circulation during exercise in mitral stenosis may induce extensive pulmonary vasoconstriction (apparently in consequence of a simultaneous elevation of the left atrial pressure), an enhanced flow rate in the pulmonary circulation during the elimination of one lung from perfusion induces an extensive dilatation of the vascular bed in the non-occluded lung.

\section{SUMMARY}

The effect of unilateral pulmonary artery occlusion by a balloon catheter on central haemodynamics was investigated in 14 subjects with pulmonary hypertension due to mitral stenosis. In 10 patients the effect of pulmonary artery occlusion was compared with the effect of exercise. A conspicuous decrease in pulmonary vascular resistance in the unoccluded lung was found during pulmonary artery occlusion. Conversely, during exercise, a small increase in the pulmonary blood flow was accompanied by a large increase in the pulmonary arterial pressure, and the pulmonary vascular resistance either did not change or showed a significant increase.

The mechanism of the different reaction of the lesser circulation to increased flow in patients with pulmonary hypertension due to mitral stenosis is discussed.

\section{REFERENCES}

Bayliss, R. I. S., Etheridge, M. J., and Hyman, A. L. (1950), Pulmonary hypertension in mitral stenosis. Lancet, 2, 889.

Brofman, B. L. (1959). Unilateral pulmonary artery occlusion. In Intravascular Catheterization, p. 637. Ed. by H. A. Zimmerman. C. C. Thomas, Springfield, Illinois.

Burton, A. C. (1959). The relation between pressure and flow in the pulmonary bed. In Pulmonary Circulation: $A n$ International Symposium, 1958, p. 26. Ed. by W. R. Adams and I. Veith. Grune and Stratton, New York.

Charms, B. L. (1961). Primary pulmonary hypertension. Effect of unilateral pulmonary artery occlusion and infusion of acetylcholine. Amer. F. Cardiol., 8, 94.

—, Brofman, B. L., and Kohn, P. M. (1959). Pulmonary resistance in acquired heart disease. Circulation, 20, 850.

Davies, L. G., Goodwin, J. F., and Van Leuven, B. D. (1954). The nature of pulmonary hypertension in mitral stenosis. Brit. Heart f., 16, 440.

Denolin, H. (1961). Contribution à l'étude de la circulation pulmonaire en clinique. Acta cardiol. (Brux.), Suppl. 10.

Donald, K. W. (1959). Pulmonary vascular resistance in mitral valvular disease. In Pulmonary Circulation: An International Symposium, 1958 p. 285. Ed. by W. R. Adams and I. Veith. Grune and Stratton, New York.

Eliasch, H., Wade, G., and Werkö, L. (1952). The effects of work on the pulmonary circulation in mitral stenosis. Circulation, 5, 271.

Fritts, H. W., Jr., and Richards, D. W. (1960). Respiratory system: external respiration. In Medical Physics, Vol. 3, p. 532. Ed. by O. Glasser. Year Book Publishers, Chicago.

Gorlin, R., Lewis, B. M., Haynes, F. W., Spiegl, R. J., and Dexter, L. (1951a). Factors regulating pulmonary "capillary" pressure in mitral stenosis IV. Amer. Heart F., 41, 834.

-, Sawyer, C. G., Haynes, F. W., Goodale, W. T., and Dexter, L. (1951b). Effects of exercise on circulatory dynamics in mitral stenosis. Amer. Heart f., 41, 192.

Harris, P. (1957). Influence of acetylcholine on the pulmonary arterial pressure. Brit. Heart f., 19, 272.

and Heath, D. (1962). The Human Pulmonary Circulation. Livingstone, Edinburgh and London. 
Hickam, J. B., and Cargill, W. H. (1948). Effect of exercise on cardiac output and pulmonary arterial pressure in normal persons and in patients with cardiovascular disease and pulmonary emphysema. $\mathcal{f}$. clin. Invest., 27, 10.

Hyland, J. W., Piemme, T. E., Alexander, S., Haynes, F. W., Smith, G. T., and Dexter, L. (1963). Behavior of pulmonary hypertension produced by serotonin and emboli. Amer. F. Physiol., 205, 591.

Semler, H. J., Shepherd, J. T., and Wood, E. H. (1959). The role of vessel tone in maintaining pulmonary vascular resistance in patients with mitral stenosis. Circulation, 19, 386.

Söderholm, B., and Werkö, L. (1959). Acetylcholine and the pulmonary circulation in mitral valvular disease. Brit. Heart f., 21, 1.

$\longrightarrow,-$, and Widimský, J. (1962). The effect of acetylcholine on pulmonary circulation and gas exchange in cases of mitral stenosis. Acta med. scand., 172, 95.
Wade, G. (1960). Elevation of the pulmonary vascular resistance. In Modern Trends in Cardiology, p. 38. Ed. by A. Morgan Jones. Butterworths, London.

Werkö, L. (1964). Mitral Vascular Disease. Almquist and Wiksell, Uppsala.

Widimský, J., and Kasalický, J. (1964). Cardiovascular adaptation to acute pulmonary hypertension. Med. thorac. (Basel), 21, 369.

$\longrightarrow,-$ and Berglund, E. (1964). The effect of repeated occlusion of the pulmonary artery on central haemodynamics. Cor et vasa (Praha), 6, 12.

Wood, P. (1956). Diseases of the Heart and Circulation, 2nd ed. Eyre and Spottiswoode, London.

- (1958). Pulmonary hypertension with special reference to the vasoconstrictive factor. Brit. Heart f., 20, 557.

-, Besterman, E. M., Towers, M. K., and McIlroy, M. B. (1957). The effect of acetylcholine on pulmonary vascular resistance and left atrial pressure in mitral stenosis. Brit. Heart f., 19, 279. 